\title{
Design and Implementation of ATM Theft Monitoring System using K-Band Doppler Radar
}

\author{
R.Sathya $^{1}$, C.Pavithra ${ }^{2}$, T.Santhiya ${ }^{3}$, Ms.L.Revathi ${ }^{4}$ \\ UG student, Department of Electronics and Communication Engineering, \\ Velalar College of Engineering and Technology, Erode, India ${ }^{1,2,3}$ \\ Assistant Professor, Department of Electronics and Communication Engineering, \\ Velalar College of Engineering and Technology, Erode, India ${ }^{4}$
}

\begin{abstract}
Automated Teller Machine (ATMs) security plays a major role in day to day life, providing protection against physical and electronic theft from ATMs and protecting their installations is much considerable since people usage is increasing steadily now a days. The aim of proposed work is to implement low cost stand-alone security system using advanced sensors like k-band Doppler radar which has a coverage area of about 360 degree. In order to improve the security here we use gas sensor which is used to detect toxic gases and RFID module that is used to provide high security.
\end{abstract}

Keywords: Arduino mega R3 Board, RFID module, RF communication, K-band Doppler radar.

\section{INTRODUCTION}

In today's technically advanced world autonomous system are gaining rapid popularity. In present environment social computerization and automation has been increased and the ATM and credit card has been installed and spread out to simplify the financial and banking activity. However the crime related with the financial organisation has been increased. The fact is that there is no safety and security for ATM systems with existing technology. Therefore this paper is going to propose a method of minimization of loss by detecting ATM machine when it has been stolen. Here by using GSM technology, Doppler radar, DC motor, advanced sensors theft of ATM machine can be predicted. In this paper we give the alert messages, sound through GSM and buzzer to the authorized person and nearby police station respectively.

\section{PROPOSED METHOD}

The main reason for this paper is to provide security for ATM. A Doppler radar is used to monitor human activities and with the help of gas sensor we can detect the toxic gases like carbon monoxide, nitrogen oxides etc. Here RFID module is used to improve the security and more efficient than magnetic cards. The coverage area of Doppler radar is greater than PIR sensor. Thus the coverage area of Doppler radar is 360 degree. Vibration sensor is used to protect the machine from strangers. Arduino mega R3 board is used in this system since it is an open source hardware and software.

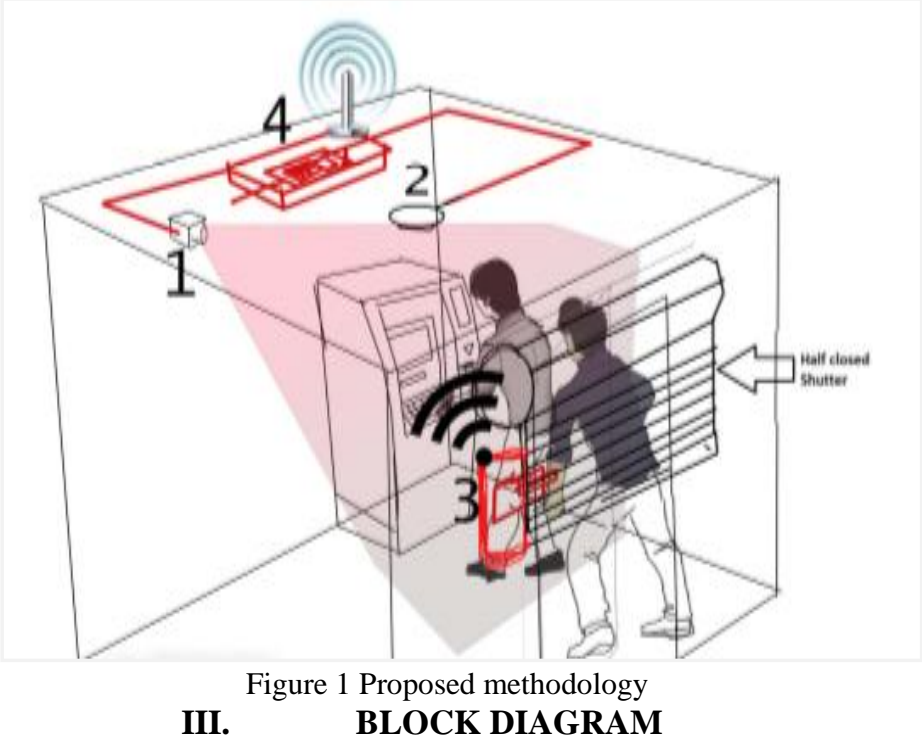


Vol. 8, Issue 2, February 2019

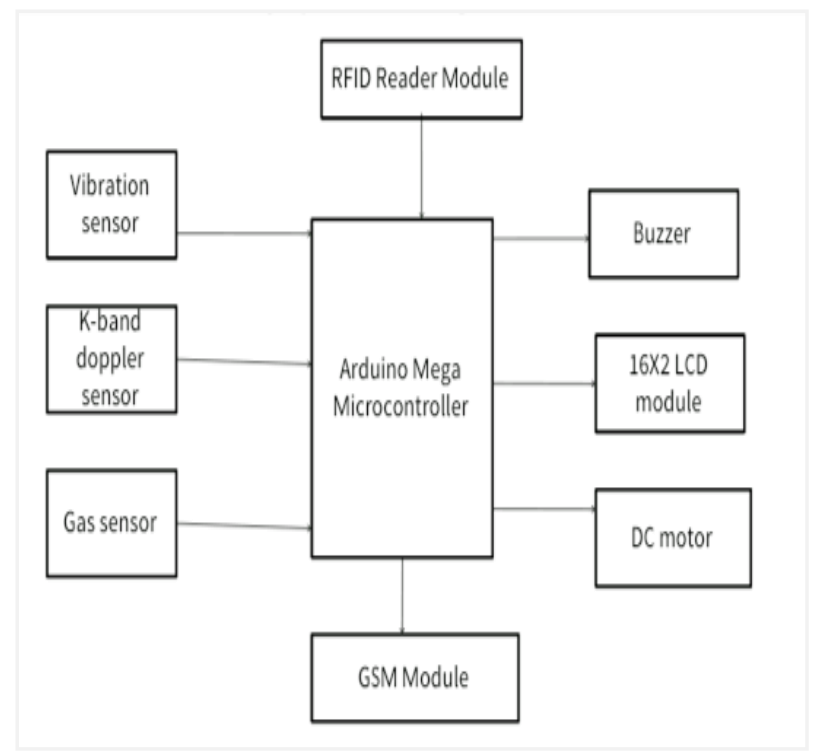

\section{A. ARDUINO MEGA R3 BOARD:}

Arduino is an open source computer hardware and software company. It provides set of digital and analog input output pins that can be interfaced to various expansion boards and other circuits. It has 54 digital input output pins, 16 analog inputs, 4 UARTs (hardware serial ports), USB connection, RESET button. The board can operate on the external supply of 6 to $20 \mathrm{~V}$.

\section{B. DOPPLER RADAR:}

Doppler radar is specialized radar that uses the Doppler Effect to produce velocity data about objects at a distance. It does this by bouncing a microwave signal off desired target and analyzing how the objects motion has alerted the frequency of the returned signal.

\section{ATmega328 MICROCONTROLLER:}

ATmega328p is an 8-bit microcontroller based on AVR RISC architecture. It has high performance, low power controller from microchip. It is used in Arduino boards which are most popular of all AVR controllers. It consists of 28 pins, which has an operating voltage of $+1.8 \mathrm{v}$ to $+5.5 \mathrm{v}$. The CPU has 8-bit AVR and flash type memory is used. It is used in Arduino UNO, Arduino NANO, Arduino micro boards. It is also used in digital data processing. Also, it finds useful applications in power regulation systems.

D. RFID MODULE:

Radio frequency identification tagging system includes internal control of fixed asserts, internal control of expensed asserts and theft prevention. The RFID system involves a Tag and a Reader. When scanned, the antenna within the tag picks up the radio wave and sense the response back to the reader.

E. VIBRATION SENSOR:

Vibration sensors are sensors for measuring, displaying and analyzing linear velocity, displacement and proximity or acceleration. Vibration analysis is used as a tool to determine equipment condition as well as the specific location and type of problems. Before taking a vibration measurement, we need to attach a sensor that detects a vibration behavior to the machine that is being measured

\section{F. GAS SENSOR:}

Gas sensor is a device that senses the presence of gases in an area, often as part of a safety system. Electro chemical sensors are most commonly used in the detection of toxic gases like carbon monoxide, chlorine and nitrogen oxides. They function via electrodes signals when a gas is detected.

\section{G. GSM MODULE:}

It is used to establish communication between a computer and a GSM system. It is a digital technology that is used to transmit information via message.

H. LCD MODULE:

LCD (Liquid Crystal Display) is an electronic display module which uses liquid crystal to produce visible image. The $16 \times 2$ module is a very basic and common display used in DIYs and circuits.

\section{WORKING}


Vol. 8, Issue 2, February 2019

The main component of this project is Doppler radar and RFID module. The advantage of using radar is that it can sense person movement behind the object also (i.e.) wall, doors etc... The entering of an authenticate person using RFID reader is placed on the outside of the shutter and is separate from the main controller unit. The controller receives the serial data from the reader and control the door. The RFID tag is kept near the RFID reader it receives the data through electromagnetic induction. Then it compares this data with the program memory. The door opens for licensed person only. Here we are using some advanced sensor like gas sensor, vibration sensor. Vibration sensor sense the vibration from ATM machine and the warning alarm is generated using buzzer and SMS is send to authorized person. Hence, propose a new security system using advanced sensors, thereby we can prevent the theft in easiest way.

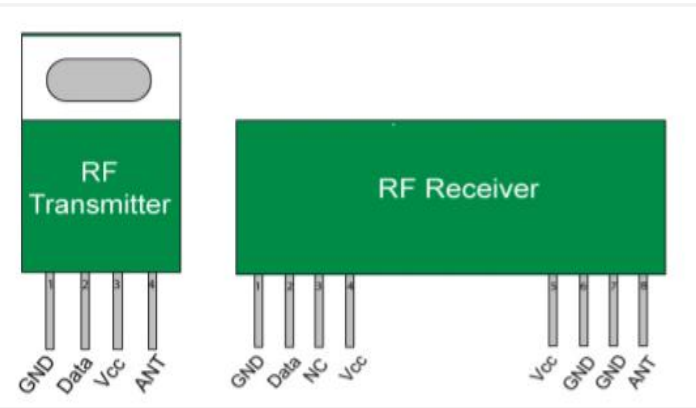

Figure 2 RFID Module

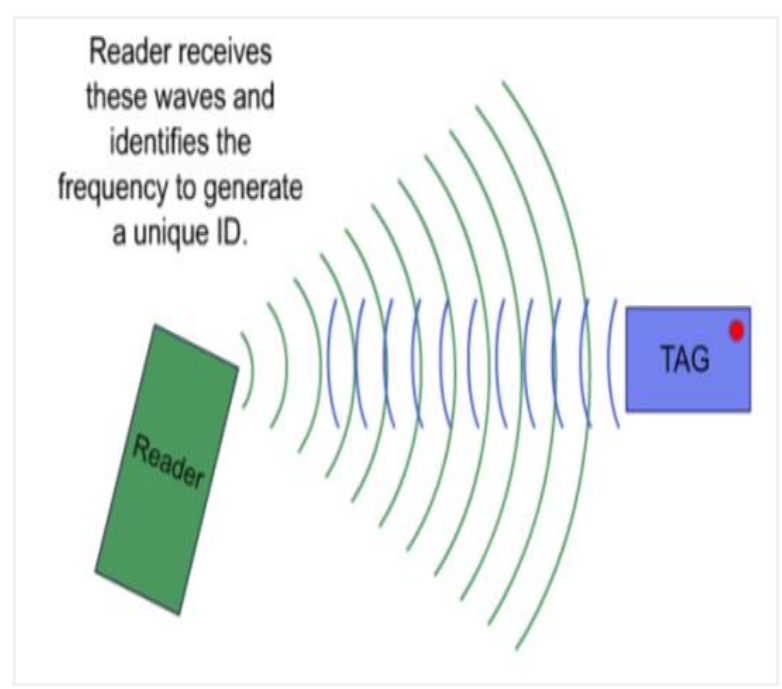

Figure 3 RFID Transmission and Reception

\section{CONCLUSION}

The proposed system ensures to develop advanced ATM Theft system. In this project advanced and low cost radar is used for ATM security has been proposed. In this method 24 hours protection is provided to ATM machine. Since advanced sensors were used for additional security like RFID module. Instead of using magnetic card, RFID module can be in order to provide high security. It is efficient, reliable, and cost effective.

\section{REFERENCES}

[1]. Assoc. Prof. Kandearchana, Dr. P. Bhaskarareddy, Dr.A. Goverdhan proposed a security system using PIR sensor. International Conference on energy, communication, data Analytics and soft computing (ICECDS-2017).

[2]. Asst.Prof.K.Hema Sai Sivaprasad,Mr.B.Kanna Vijay Proposed an Anti-Theft ATM machine using Embedded Systems. International Journal\&Magazine of Engineering, Technology, Managementand Research (2016).

[3]. Kannamma, M.Barathi, B.Chanthini and D.Manivannan proposed a "controlling and monitoring process in industrial automation using zigbee".Advances in computing, communications and informatics (ICACCI), 2013 International conference on IEEE (2013).

[4]. Ajay kumar.M (2013).“Anti-theft ATM machine using vibration detection sensor" International journal of advanced research in computer science and software engineering.

[5]. Kannan.P and Mis.P.Meenakshividya. "Design and implementation of security based ATM theft monitoring system". 